\title{
Spennrath-Kirstein
}

\section{Grundlagen der Elektrotechnik.}

I. Teil. 


\title{
Grundlasen der Elekitrotechnik
}

von

\section{O. Kirstein}

Beratender Ingenieur.

\section{Dritte neubearbeitete Auflage von:}

Die Bedienung und Wartung elektrischer Anlagen und Maschinen

von

\section{Jos. Spennrath}

weil. Direktor der städt. gew. Schulen usw. in Aachen.

I. Teil: Einführung in die Grundlagen der Elektrotechnik.

II. Teil: Einführung in den Bau und die Wirkungsweise der elektrischen Maschinen.

\author{
Berlin W \\ Verlag von M. Krayn. \\ 1923.
}




\section{Einfiuhrung in die}

Grundlagen der Elekitrotechnik von

Joseph Spennrath.

Dritte neubearbeitete Auflage

von

O. Kirstein

Beratender Ingenicur.

Mit 135 Abbildungen im Text.

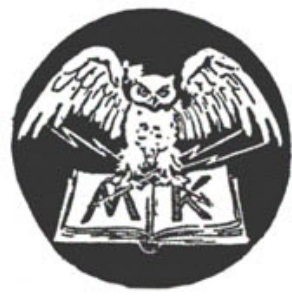

Berlin W

Verlag von M. Krayn.

1923. 
Alle Rechte vorbehalten, namentlich das der Übersetzung. 